\title{
Experimental and Numerical Examination on Heat Transfer Enhancement using Twisted Tapes
}

\author{
K.D Jaganathan, S. Sam Godwin Sathyaraj, M. Sivasubramanian
}

\begin{abstract}
Recent years amply of researchers doing research in enhancement of heat transfer by applying passive heat transfer technique. Recently usage of twisted tape insert to increase the heat transfer surface area is the most preferable passive technique followed by numerous researchers. To increase the complexity of the situation and properly implement the heat transfer enhancement method creating geometrical changes on the twisted tape is leading to a various study of flow physics. In this present review enhancement of heat transfer using insertion of twisted tape investigated numerically and experimentally is reported based on the past decade researches. This review will enable the researchers to involve in diversified usage of twisted tape inserts in the flow field to report the flow physics in detailed manner. This review depicts the findings of experimentally and numerically investigated research works of influence of twisted tape inserts on heat transfer enhancements.
\end{abstract}

Keywords - Twisted tape inserts, Heat transfer augmentation, swirl flow, heat transfer enhancement, Twist ratio, Reynolds number

\section{INTRODUCTION}

Cooling the equipments without affecting its performance is a major issue in the current scenario. Various cooling techniques were used in many sectors like food industries, electronics, space applications, automobiles, air conditioning petro chemical, solar heater, refrigeration, petrochemical, automobiles and manufacturing industry. Need of heat transfer enhancement in the industries is one of the major attention for more than 30 to 35 years [1]. This motivates the researchers to work in this field during 1960's [2]. The size and shape of the heat exchanger plays a major role for its effective usage. Studies on the compact heat exchanger were discussed by many authors [3-5]. Placing of twisted tape in the round duct is an easiest passive technique for augmenting the convective coefficient of heat transfer [6].Different

Revised Manuscript Received on July 22, 2019

* M Sivasubramanian

K.D.Jaganathan, Assistant Professor, Department of Mechanical Engineering, SACS MAVMM Engineering college, Madurai, Tamil Nadu, India. Email: jaganathan1978@gmail.com

Sam Godwin Sathyaraj, Research Scholar, Department of Automobile Engineering, School of Automotive and Mechanical Engineering, Kalasalingam Academy of Research and Education, Tamilnadu - India. Email:samgodwin92@gmail.com

M Sivasubramanian*, Department of Automobile Engineering, School of Automotive and Mechanical Engineering, Kalasalingam Academy of Research and Education, Tamilnadu - India. Email: m.sivasubramanian@klu.ac.in material like aluminum and copper were used to made Twisted tapes with varying thickness of $0.8 \mathrm{~mm}$ to $1 \mathrm{~mm}$ and length around $1000 \mathrm{~mm}$. Twisted tapes are the straight metallic strips with definite shapes with varying geometrical dimensions and are placed in and across the flow directions. Using of twisted tape is low cost and very easy to implement. Passive techniques provides more coefficient of heat transfer and with high drop in pressure [7]. Insertion of twisted tapes and inserts in the flow passage has a reduces in diameter and free flow path. This creates flow blockage and separation of flow. The separation generates the secondary flow. This secondary flow produces the swirl motion and gives good fluid mixing results in the enhancement of temperature gradient and thus effective heat transfer occurs [8, 9]. Passive methods do not need any outside power to enhance the heat transfer [10]. The methods used in the passive heat transfer include modification of the surface geometry like treated surfaces, surface coating, rough surfaces, extended surfaces, Swirl flow devices [11]. Many authors have worked on the twisted tape to enhance the heat transfer in experimentally and numerically. In this paper an effort has been carried out to review the experimental and numerical analysis of the various researchers for heat transfer enhancement techniques.

\section{LITERATURE REVIEW}

Yu-Wei Chiu, Jiin-Yuh Jang [12] Study on the heat transfer coefficient for the longitudinal strip with and without holes and twisted tape with three different twist angles $\alpha=15.3^{\circ}$, $24.4^{\circ}$ and $34.3^{\circ}$ were investigated numerically and experimentally. Numerical methods were carried out using commercial software. Finite volume methods were used to solve the governing equation. Total grid numbers were varied for different cases. The experimentation was carried using shell and tube heat exchanger. Air is used as the working fluid. It is seen that the flow speed is motivated to $40 \%$ more than the inlet frontal velocity. This is due to the presence of twisted tape which generates the flow field distortion. The numerical and experimental results for the pressure drop per unit length and the Reynolds number were observed. The pressure drop for the longitudinal strip with and without holes was 25 to $60 \%$ and 100 to $120 \%$ more than the plain tube. Twisted tape with twist angle $\alpha=34.3^{\circ}$ shows maximum pressure drop. The pressure drop for the longitudinal strip with holes shows a raise of 5-56\% more than the twisted-tape with twist angle of $\alpha=15.3^{\circ}$. Numerical and the experimental results for the pressure drop show a good concurrence within the range of $12-21 \%$. 


\section{Experimental and Numerical Examination on Heat Transfer Enhancement using Twisted Tapes}

Mean Nusselt number and the Reynolds number for varying inserts were also analyzed in both the method. The Nusselt number for the longitudinal strip with and without holes was also observed. It is seen that Nusselt number for the longitudinal strip with holes, without holes and for varying twist angle of $\alpha=15.3^{\circ}, 24.4^{\circ}$ and $34.3^{\circ}$ were $13-28 \%, 7-$ $16 \%$ and $13-61 \%$ more than the plain tube. It is also seen that the heat transfer coefficient performance for the twisted tape with twist angle of $\alpha=34.3^{\circ}$ shows good output than other twist angles. The mean Nusselt number for $\alpha=34.30$ shows an increasing of $12-27 \%, 17-40 \%, 27-60 \%$ more than that for the longitudinal strip inserts with holes, without holes and plain tube.

Masoud Rahimi et al [13] Study on the friction factor, Nusselt number and thermal-hydraulic performance on a tube integrated with classic, perforated, notched and jagged twisted tape inserts were analyzed experimentally and numerically. Twisted tape material used for the experimentation is stainless steel and having the pitch length of $50 \mathrm{~mm}$. Numerical method were carried out using $\mathrm{k}-\varepsilon$ turbulent model. Convergence criterion of $10^{-4}$ was preferred for all calculated parameters. The outcome shows that presence of twisted tape inserts increase the Reynolds number and the Nusselt number. Increase in the Nusselt number shows the augment of heat transfer performance. Presence of inserts raises the tangential velocity and reduces the cross sectional area of the flow. This reduction of the area cross section generates the eddy flow which enhances the heat transfer performance. The experimental results shows that the jagged twisted tape inserts performs well compare to other inserts. It is observed that presence of jagged twisted tape inserts increases the Nusselt number and the overall performance by $31 \%$ and $22 \%$ than other inserts. The CFD modeling was used to analyses the experimental work. It shows that the jagged twisted tape inserts produce higher turbulence of the fluid at the wall. This makes the increase of the performance than the other twisted tapes. Maximum performance at low Reynolds number, geometry of the jagged twisted tape and the raise of the turbulence at the wall make the jagged inserts to attract the investigators than the other types.

CUI Yong-zhang and TIAN Mao-cheng [14] Experiments and 3D numerical work has been carried to analyze the effect of heat transfer, friction factor and thermal-hydraulic performance using Edge fold twisted tape (ETT) and spiral twisted tape (STT). The experiments were carried out using air as the working fluid with varying Reynolds number of 2,500 to 9,500 and twist ratio of 5.4 to 11.4. The experimentation result incur that the tube with ETT shows an augment in heat transfer compared to the STT. Nusselt number and friction factor for ETT were $3.9 \%$ to $9.2 \%$ and $8.7 \%$ to $7.4 \%$ more than the STT. Thermal hydraulic performances are in the range of 0.91 to 1.01 . It is observed that enhanced heat transfer was seen for ETT. ETT generates high tangential velocity and irregular shape generates irregular velocity profiles and raise and slowdown of the velocity within the edgefold length. Twist angle also plays an important role on the performance. Larger twist angle increases the Nusselt number and the friction factor. The gap width also plays a major role for the heat transfer and the minor effect on the pressure drop. Reducing the gap width from $1.5 \mathrm{~mm}$ to $1.0 \mathrm{~mm}$ and $0.5 \mathrm{~mm}$ the Nusselt number rises by $7.1 \%$ and $23.7 \%$ and the friction factor rises by $3.2 \%$ and $12.1 \%$. Thermal hydraulic performance rises in the average of $124 \%$ and $140 \%$. As the gap width increases, the velocity of the air is amplified and reduces the main velocity and the tangential velocity. So it is necessary to select minimum gap velocity to attain the best performance. The numerical output shows an equitable result with the experimental results with the range of $1.6 \%$ to $3.6 \%$ for the Nusselt number and $8.2 \%$ to $13.6 \%$ for the friction factor.

S.R. Shabanian et al [15] Study on performance on the heat transfer, friction factor and thermal performance factor for classic, butterfly and jagged twisted tape inserts were analyzed experimentally and numerically. Three different angles of $45^{\circ}, 90^{\circ}$ and $135^{\circ}$ were used in the butterfly inserts. The experimental results shows that the Presence of twisted tape reduce the flow area and raises the turbulence and tangential flow thereby the Nusselt number get increased. For all Reynolds number the jagged twisted tape inserts shows a raise in the Nusselt number than the classic twisted tape and both jagged and classic inserts enhance the heat transfer as the twist ratio reduces. Heat transfer rate for jagged twisted tape with minimum twist ratio of 1.76 shows 16.9 to $19.3 \%$ more than the maximum twist ratio of 3.53 and 95.6 to $157.5 \%$ more than the plain tube. Butterfly insert twisted tape with an angle of $90^{\circ}$ performs high Nusselt number than other angle of $45^{\circ}$ and $135^{\circ}$. Tube with the twisted tape shows an increase in the friction factor than the plain tube. Twisted tape with less twist ratio tends to increase viscous loss near the tube wall this leads to the friction factor raises with the reduce in the twist ratio of the twisted tape. Jagged twisted tape with minimum twist ratio of 1.76 shows raise in the friction factor by $28.7-43.5 \%$ and $502-818 \%$ than the jagged twisted tape with maximum twist ratio of 3.53 and the plain tube. Jagged twisted tape with twist ratio of $1.76,2.35,2.94$ and 3.53 shows a friction factor of $10.65 \%, 20.57 \%, 30.19 \%$ and $34.41 \%$ more than the classic twisted tape and classic twisted tape with twist ratio of $1.76,2.35,2.94$ and 3.53 shows a friction factor of $6.38,5.48,4.66$ and 3.84 times than the plain tube. It is also observed that the thermal performance factor varies from 1.28 and $1.62,1$ and 1.23 and 0.88 and 1.03 for the butterfly, jagged, and classical twisted tape depend on the Reynolds number and the inclination angle or the twist ratio. Butterfly twisted tape with $90 \mathrm{o}$ angle shows thermal performance factor of 14.5 to $17.2 \%$ and 6.4 to $10.2 \%$ more than $45^{\circ}$ and $135^{\circ}$ angle. Jagged twisted tape with a minimum twist ratio of 1.76 shows thermal performance factor of $2.5 \%$, $5.2 \%$ and $7.1 \%$ more than the other twist ratios. Thermal performance factor for jagged twisted tape with twist ratio $1.76,2.35,2.94$ and 3.53 are $13.3 \%, 14.6 \%, 15.5 \%$ and $16.9 \%$ more than the classic twisted tapes. Numerical results show that Nusselt number and the friction factor correlates with the experimental results with a minimum error of less than $7 \%$. It also concluded that the butterfly inserts generates turbulence effect in the flow results in increase in the performance than the jagged and classical twisted tapes.

S. Eiamsa-ard et al [16] experiments were conducted for uniform twisted tape with alternate axis (TAs), non-uniform twisted tape with alternate axis (N-TAs) and the results were compared with the typical 
twisted tape (TT) and the plain tube.

The TAs and N-TAs were made of aluminium strip. Numerical work has also been carried out to validate the experimental work. The results shows that Nusselt number for the TAs were enhanced by $30 \%$ to $55 \%$ than the Plain tube. TAs with small alternate length to twist length (1/y) performs maximum Nusselt number than the other $1 / y$. Nusselt number for TAs with varying alternate length to twist length of 0.5 , $1.0,1.5$ and 2.0 were $52 \%, 47 \%, 43 \%$ and $37 \%$ more than TT. TAs with smaller 1/y performs good fluid mixing, steady flow fluctuation and thus better heat transfer. It is seen that flow restriction, eddy flow and turbulence at the every alternate point generates enhanced dissipation of dynamic pressure leads the friction factor raises by $10 \%$ to $50 \%$ more than the TT. Friction factor and thermal performance factor for varying $1 / y$ were $47 \%, 38 \%, 27 \%$ and $15 \%$ and $20 \%, 16 \%$, $12 \%$ and $7 \%$ more than TT. The comparison between the TAs and N-TAs were also carried out. The results shows that the augment in heat transfer for all N-TAs were compared with TAs. It is seen that there is a small decrement in heat transfer and friction factor for $1 / y$ ratio of 0.5 and 1.0 by $12 \%$ and $4 \%$ and $10-20 \%$ and $5-10 \%$. It is also seen that N-TAs with alternate length performs a major role for the augment of heat transfer and friction factor. TAs and N-TAs shows more turbulence at the adjacent points generates good fluid mixing and increase the heat transfer rate than the TT. The numerical results also approved the experimental results and concluded that thetas and N-TAs shows good fluid mixing and increase in Nusselt number were achieved than the TT.

P. Eiamsa-ard et al [17] influence on the effect of regularly-spaced twisted tape (RS-TT) on the heat transfer, friction factor and thermal performance factor behaviors were analyzed and were compared with the full length twisted tape. Two different twist ratios for full length twisted tape and three different free space ratio of $\mathrm{S} / \mathrm{P}=1.0,2.0$ and 3.0 for regularly-spaced twisted tape (RS-TT) and Reynolds number of 5,000 and 12, 0000 were considered for the investigation. Numerical work were also been carried out for RS -TT, to study about the fluid flow behavior, Nusselt number characteristics and fluid temperature in the turbulent regime. The results shows that the full length twisted tape generates nonstop eddy flow for the entire length of the twisted tape and RS-TTs generates discontinuous eddy flow and decompose along the free space leads the full length twisted tape bring out maximum heat transfer rate, friction factor and thermal performance factor than regularly-spaced for the space ratio of 1.0, 2.0 and 3.0. It is seen that heat transfer enhancement, friction factor and thermal performance factor reduces with rise in space ratio. For the identical twist ratio and space ratio of $0,1.0,2.0$ and 3.0 there is an increasing trend in heat transfer enhancement and friction factor of $56.8 \%, 46.2 \%$, $30.5 \%$ and $22.6 \%$ and $4.22,3.78,3.17$, and 2.63 times than the plain tube. It is also observed that the heat transfer and the friction factor reduce with rise in the twist ratio. Twist ratio of 6.0 shows an increase in Nusselt number than twist ratio of 8.0 around $6.9 \%$ for the identical space ratio. Small twist ratio produce muscular eddy flow results in elevation in the shear force on the tube wall and efficient thermal boundary distribution leads to enhance in the heat transfer. For the identical space ratio and twist ratio of 6.0 and 8.0 the heat transfer augment and the friction factor were $46.2 \%$ and $34.6 \%$ and 3.78 and 3.21 times than the plain tube. Thermal performance factor rises with decrease in the twist ratio, free space ratio and the Reynolds number. RS-TTs with space ratio $0,1.0,2.0$ and 3.0 and the twist ratio 6.0 , the thermal performance factor lies between 0.86 and $0.97,0.82$ and 0.94 , 0.79 and 0.89 , and 0.78 and 0.88 . Aditi Uday

Desai et al [18] Experimental and Numerical analyses were carried out on heat transfer characteristics using centrally cleared two twisted tapes and were compared with the single twisted tape. Investigations were carried out for the Reynolds number of 45, 000. The outcomes shows that pipe with two twisted tapes improve the flow path near the tube wall this leads to augment the heat transfer. Heat transfer coefficient for two tapes is enhanced by $2.18 \%$ to $10.1 \%$ than the single twisted tape. Friction factor gets boosted for two twisted tape due to its turbulence created in the flow than the single twisted tape. Presence of the central clearance maintains the pressure drop inside the tube. It also seen that maximum pressure is obtained for two twisted tape and twist ratio of 3 . The pressure drop is same for the two twisted tape and for twist ratio 5 and single twisted tape and has the variation of 5\% only. Yogesh B. Rakate et al [19] Study on the heat transfer using with and without twisted tapes with three different twist ratios, varying mass flow rates of $0.003 \mathrm{Kg} / \mathrm{sec}$ to $0.005 \mathrm{Kg} / \mathrm{sec}$ and heat flux were analyzed experimentally. Air is used as the working fluid. The experimental results were compared with the numerical results. The experimental outcome shows that twist ratio of 3.64 shows an enhanced heat transfer rate than plain tube and other twist ratios. The Numerical outcome correlates well with the experimental results. Difference of $7^{\circ} \mathrm{C}$ was observed for the twist ratio 3.64 and plain tube. 
TABLE 1 SUMMARY OF THE REVIEW REPORT

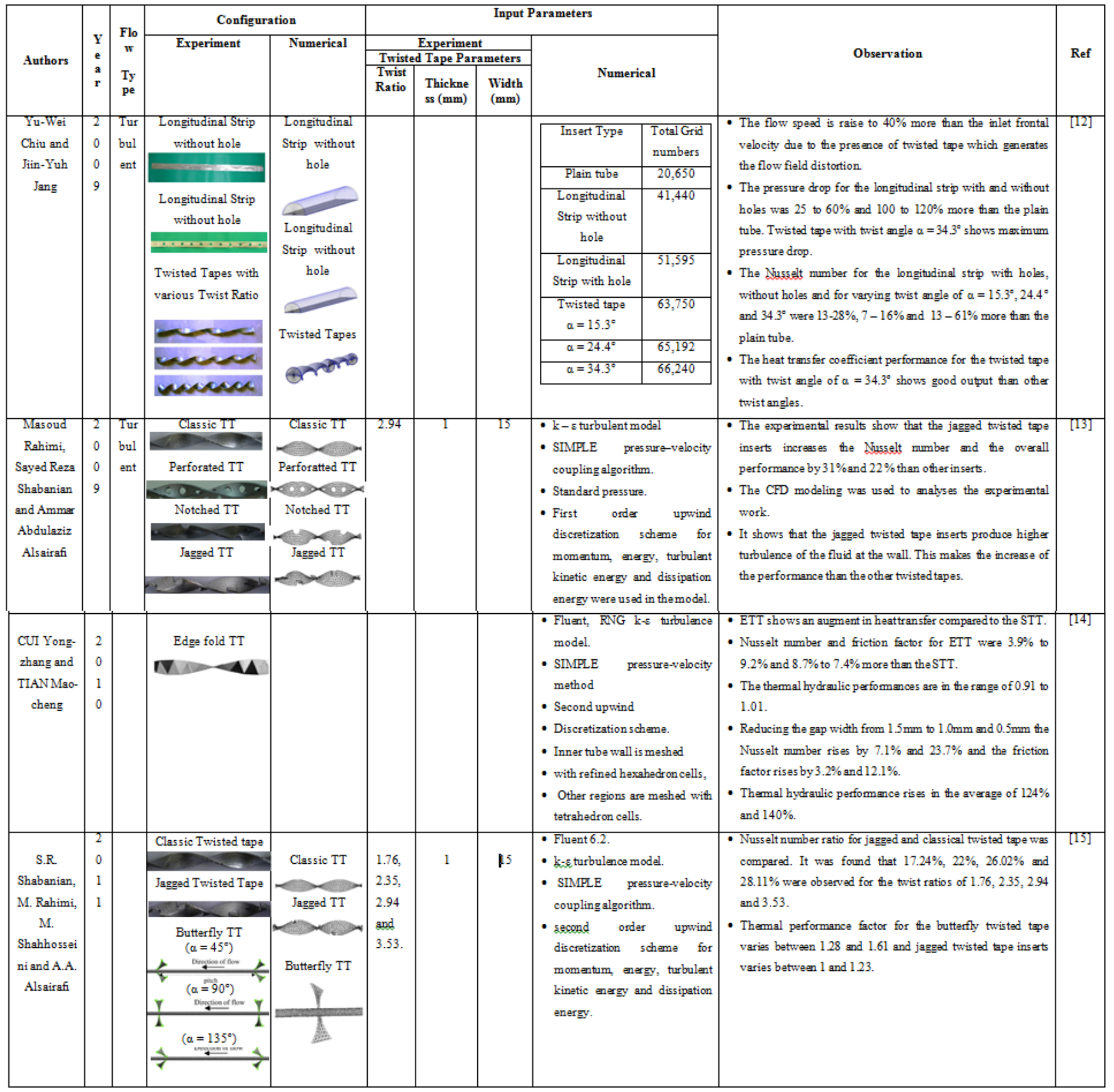




\begin{tabular}{|c|c|c|c|c|c|c|c|c|c|c|}
\hline $\begin{array}{l}\text { S. Eiamsa- } \\
\text { ard, P. } \\
\text { Somkleang } \\
\text { C. } \\
\text { Nuntadusit } \\
\text { and C. } \\
\text { Thianpong }\end{array}$ & $\begin{array}{l}2 \\
0 \\
1 \\
3\end{array}$ & & 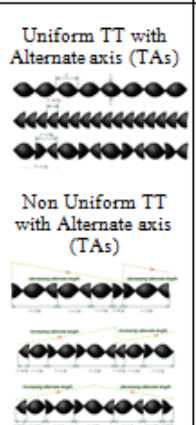 & & $\begin{array}{l}3,4 \\
\text { and } 5\end{array}$ & 0.8 & 18 & $\begin{array}{l}\text { - Time-independent } \\
\text { incompressible Navier Stokes } \\
\text { equations. } \\
\text { - RNG k-apsilon turbulence } \\
\text { model. } \\
\text { - QUICK, SMPLE method and } \\
\text { Central differencing mumerical } \\
\text { schemes and were applied. }\end{array}$ & $\begin{array}{l}\text { - Small decrement in heat transfer and friction factor for ly } \\
\text { ratio of } 0.5 \text { and } 1.0 \text { by } 12 \% \text { and } 4 \% \text { and } 10-20 \% \text { and } 5-10 \% \\
\text { - N-TAs with altemate length performs a major role for the } \\
\text { augment of heat transfer and frictionfactor. } \\
\text { - TAs and N-TAs shows more turbulence at the adjacent point } \\
\text { generates good fluid mixing and increase the heat transfer rate } \\
\text { than the TT. } \\
\text { - Numerical results also approved the experimental results and } \\
\text { conchuded that thetas and N-TAs shows good fluid mixing and } \\
\text { increase in Nusselt number were achieved than the TT. }\end{array}$ & [16] \\
\hline $\begin{array}{l}\text { P. Eiamsa- } \\
\text { ard, } \\
\text { N. } \\
\text { Piriyarungr } \\
\text { oj, } \\
\text { C. } \\
\text { Thianpong, } \\
\text { S. Eiamsa- } \\
\text { ard }\end{array}$ & $\begin{array}{l}2 \\
0 \\
1 \\
4\end{array}$ & $\begin{array}{l}\text { Tur } \\
\text { bul } \\
\text { ent }\end{array}$ & RS-TTs Inserts & & $\begin{array}{l}6.0, \\
8.0\end{array}$ & $\begin{array}{c}\text { RS-TTS } \\
=1\end{array}$ & $\begin{array}{c}\text { RS- } \\
\text { TTS = } \\
18\end{array}$ & $\begin{array}{l}\text { - Time-independent } \\
\text { incompres sible Navier-Stokes } \\
\text { equations. } \\
\text { - Turbulence model were } \\
\text { discretized. } \\
\text { - QUICK, SIMPLE method and } \\
\text { Central differencing mmerical } \\
\text { schemes and were applied. } \\
\text { - Total number of elements for } \\
\text { S=0,1.0,2.0 and } 3.0 \text { were } \\
401583,385801,386394 \text { and } \\
379073 \text {. }\end{array}$ & $\begin{array}{l}\text { - Full length twisted tape bring out maximum heat transfer rate, } \\
\text { friction factor and thermal performance factor than regularly- } \\
\text { spaced for all the space ratios. } \\
\text { - Identical twist ratio and for all space ratios increasing trend in } \\
\text { heat transfer enhancement and friction factor of } 56.8 \% \text {, } \\
46.2 \%, 30.5 \% \text { and } 22.6 \% \text { and } 4.22,3.78,3.17 \text {, and } 2.63 \text { times } \\
\text { than the plain tube were observed. } \\
\text { - RS-TTs with space ratio } 0,1.0,2.0 \text { and } 3.0 \text { and the twist ratio } \\
6.0 \text {, the thermal perfomance factor lies between } 0.86 \text { and } \\
0.97,0.82 \text { and } 0.94,0.79 \text { and } 0.89 \text {, and } 0.78 \text { and } 0.88 \text {. }\end{array}$ & [17] \\
\hline $\begin{array}{l}\text { Aditi Uday } \\
\text { Desai, R. } \\
\text { D. Shelke } \\
\text { and H. N. } \\
\text { Deshpande }\end{array}$ & $\begin{array}{l}2 \\
0 \\
1 \\
6\end{array}$ & & $\begin{array}{l}\text { Two Twisted tape } \\
\text { Single Twisted tape }\end{array}$ & & & & & $\begin{array}{l}\text { - ANSYS is used for Numerical } \\
\text { simulation to study the flow } \\
\text { pattern and the performance of } \\
\text { the geometry of the two tapes. }\end{array}$ & $\begin{array}{l}\text { - The outcomes shows that pipe with two twisted tapes improve } \\
\text { the flow path near the tube wall this leads to augment the heat } \\
\text { transfer. } \\
\text { - Heat transfer coefficient for two tapes is enhanced by } 2.18 \% \\
\text { to } 10.1 \% \text { than the single twisted tape. } \\
\text { - Maximum pressure is obtained for two twisted tape and twist } \\
\text { ratio of } 3 \text {. }\end{array}$ & [18] \\
\hline $\begin{array}{c}\text { Yogesh B. } \\
\text { Rakate, } \\
\text { Kunal } \\
\text { Bhavsar } \\
\text { and S.S. } \\
\text { Umale }\end{array}$ & $\begin{array}{l}2 \\
0\end{array}$ & & Twisted Tape & $\begin{array}{l}\text { Meshing of TT } \\
\text { with Twist ratio } \\
\quad=9.09\end{array}$ & $\begin{array}{l}9.09 \\
6.05 \\
\text { and } \\
3.64\end{array}$ & 2 & 22 & $\begin{array}{l}\text { - CATIA V5 software is used for } \\
\text { the physical model of the } \\
\text { twisted tape. } \\
\text { - Meshing was carried out using } \\
\text { ANSYS ICEM CFD } 14.5 \text {. } \\
\text { - Volume mesh is carried out by } \\
\text { tetrahedron and prism meshing } \\
\text { to capture } \\
\text { - The total numbers of elements } \\
\text { created were } 121880 \text {. }\end{array}$ & $\begin{array}{l}\text { - Experimental outcome shows that twist ratio of } 3.64 \text { shows an } \\
\text { enhanced heat transfer rate than plain tube and other twist } \\
\text { ratios. } \\
\text { - Numerical outcome also correlates well with the experimental } \\
\text { results. } \\
\text { - Difference of } 7^{\circ} \mathrm{C} \text { was observed for the twist ratio } 3.64 \text { and } \\
\text { plain tube. }\end{array}$ & [19] \\
\hline
\end{tabular}




\section{CONCLUSION}

This review reports the influence of twisted tape insert in the flow path on enhancement of heat transfer. Experimentally and numerically investigated investigations were reported. The influence of twist ratio, geometry and other peripheral changes on the twist tape inserts reports that the heat transfer was greatly influenced by the insert. All the research reported used twist tape in axial directions or along the flow path only. No research were reported that the inserts in transvers direction of the flow. Hence the review enables the researchers to carryout research in usage of twisted tape in transverse direction of the flow. The summery of the review reported in table 1 .

\section{REFERENCES}

[1] S.Ray and A.W.Date, "Laminar flow and heat transfer through square duct with twisted tape insert", International Journal of heat and fluid flow 22, (2001), $460-472$.

[2] Arthur E. Bergles and Harmon L.Morton, "Survey and evaluation of techniques to argument convective heat transfer", 1965, Technical Report No $5382-34$.

[3] F. A. Creswick, S. G, Talbert, and J. W. Bloemer, "Compact Heat-Exchanger Study", April 15, 1964, 1 - 58.

[4] K. M. Stone, "Review of Literature on Heat Transfer Enhancement in Compact Heat Exchangers", 1996, 1- 39.

[5] L. Wang and B. Sunden, "Performance comparison of some tube inserts," International Communication in Heat Mass Transfer, Vol. 29 (1), pp. 45-56, 2002.

[6] S. Ray, A.W. Date, "Friction and heat transfer characteristics of flow through square duct with twisted tape insert", International Journal of Heat and Mass Transfer 46 (2003) 889-902.

[7] Mohsen Sheikholeslami, Mofid Gorji-Bandpy, Davood Domiri Ganji, "Review of heat transfer enhancement methods: Focus on passive methods using swirlflow devices", Renewable and Sustainable Energy Reviews 49 (2015) 444-469.

[8] A Dewan, P Mahanta, K Sumithra Raju and P Suresh Kumar, "Review of passive heat transfer augmentation Techniques", Proc. Instn Mech. Engrs Vol. 218 Part A: J. Power and Energy, DOI: 10.1243/0957650042456953, 509-527.

[9] Varun, M.O. Garg, Himanshu Nautiyal, Sourabh Khurana and M.K. Shukla, "Heat transfer augmentation using twisted tape inserts: A review", Renewable and Sustainable Energy Reviews 63 (2016) 193-225.

[10] S. Tabatabaeikia, H. A. Mohammed N. Nik-Ghazali and B. Shahizare, "Heat Transfer Enhancement by Using Different Types of Inserts", Advances in Mechanical Engineering, Volume 2014, Article ID 250354, 13 pages, http://dx.doi.org/10.1155/2014/250354.

[11] A. E. Bergles, "Heat Transfer Enhancement - The Encouragement and Accommodation of High Heat Fluxes", Transactions of the ASME, Vol. 119, February 1997, pp: 8-19.

[12] Yu-Wei Chiu, Jiin-Yuh Jang, "3D numerical and experimental analysis for thermal-hydraulic characteristics of air flow inside a circular tube with different tube inserts", Applied Thermal Engineering 29 (2009) 250-258.

[13] Masoud Rahimi, Sayed Reza Shabanian and Ammar Abdulaziz Alsairafi, "Experimental and CFD tudies on heat transfer and friction factor characteristics of a tube equipped with modified twisted tape inserts", Chemical Engineering and Processing 48 (2009) 762-770.

[14] CUI Yong-zhang and TIAN Mao-cheng, "Three-dimensional numerical simulation of thermal- hydraulic performance of a circular tube with edgefold-twisted-tape inserts", 2010,22(5):662-670, DOI: 10.1016/S1001-6058(09)60101-3.

[15] S.R. Shabanian, M. Rahimi, M. Shahhosseini and A.A. Alsairafi, "CFD and experimental studies on heat transfer enhancement in an air cooler equipped with different tube inserts", International Communications in Heat and Mass Transfer 38 (2011) 383-390.

[16] S. Eiamsa-ard, P. Somkleang, C. Nuntadusit and C. Thianpong, "Heat transfer enhancement in tube by inserting uniform/non-uniform

twisted-tapes with alternate axes: Effect of rotated-axis length", Applied Thermal Engineering 54 (2013) 289 -309.

[17] P. Eiamsa-ard, N. Piriyarungroj, C. Thianpong, S. Eiamsa-ard, "A case study on thermal performance assessment of a heat exchanger tube equipped with regularly-spaced twisted tapes as swirl generators", http://dx.doi.org/10.1016/j.csite.2014.04.002.

[18] Aditi Uday Desai, R. D. Shelke and H. N. Deshpande, "Numerical and Experimental Study of Heat Transfer Characteristics with Centrally Cleared Two Twisted Tapes", International Journal of Current Engineering and Technology, E-ISSN 2277 - 4106, P-ISSN 2347 5161.

[19] Yogesh B. Rakate, Kunal Bhavsar and S.S. Umale, "Experimental and Numerical Analysis of Heat Transfer Augmentation Through a Pipe using Twisted Tapes", IJIRST -International Journal for Innovative Research in Science \& Technology, Volume 2, Issue 10, March 2016.

\section{AUTHORS PROFILE}

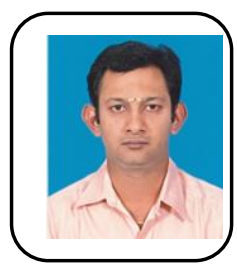

Jaganathan. K.D obtained his Bachelor's Degree in 1999 from Madurai Kamaraj University. Further completed his Master's degree in Computer Integrated Manufacturing from Visvesvaraya Technological University, Belagavi, India in 2001 His research interest includes fluid dynamics, experimental heat transfer and flow separation using CFD techniques. Currently working on the above said research area and published an international journal and communicated three international journals. He started his career as teaching faculty from 2004 and currently working as Assistant Professor in the Department of Mechanical Engineering, SACS MAVMM Engineering College, Kidaripatti, Madurai, India. He holds life membership in Indian Society for Technical Education (ISTE), India.

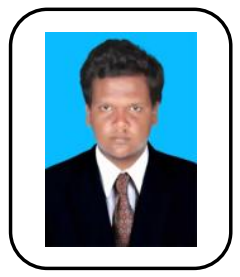

S. Sam Godwin Sathyaraj is a Research Scholar at Department of Automobile Engineering in Kalasalingam Academy of Research and Education, Krishnankoil. He holds Master of Engineering (Engineering Design) from SVS College of Engineering, Coimbatore and Bachelor of Engineering (Mechanical) from Kalasalingam University, Krishnankoil.

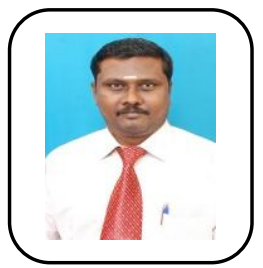

Sivasubramanian. M obtained his Bachelor's Degree in 1999 from Madurai Kamaraj University. Further he completed his Master's degree in Production Engineering from Anna University, India in 2005. He was awarded with Ph.D. degree in Faculty of Mechanical Engineering in the year 2015. During his research career he has published 14 International journals and participated and published many International conferences papers. He actively involved in inventing things related to automobile and mechanical engineering and as an outcome of this, he has registered 19 patents in INDIA. One of his inventions is eco-friendly hybrid electric car with self-electrical charging for which he received a fund of One lakh Rupees from Innovation and Entrepreneurship Development Centre, National Science \& Technology Entrepreneurship Development Board (NSTEDB) Department of Science \& Technology Department of Science and Technology. His research interest includes fluid dynamics, conjugate heat transfer, experimental heat transfer and flow separation using CFD techniques. He started his career as teaching faculty from 1999 and currently working as an Associate Professor in the Department of Automobile Engineering, Kalasalingam Academy of Research and Education, India. He holds life membership in Life member in Indian Society for Heat and Mass Transfer (ISHMT), India and Life member in Indian Society for Technical Education (ISTE), India. 